\title{
CYSTEAMINE IMPROVES THE BACTERICIDAL EFFICACY OF INTRA-CANAL MEDICAMENTS AGAINST ENTEROCOCCUS FAECALIS
}

\section{SANKET HANS PANDEY, PALLAV MAHESH PATNI, PRADEEP JAIN, GAURI SANWATSARKAR, CHINKI BARDIA}

\author{
Conservative Dentistry and Endodontics Department, Madhya Pradesh Medical \\ Science University, India
}

\begin{abstract}
Aim. The aim of this study was to compare the antimicrobial efficacy of cysteamine, calcium hydroxide[Ca(OH)2], triple antibiotic paste (TAP), chlorhexidine (CHX) and their combinations against Enterococcus faecalis (E. Faecalis).

Methods. The E. Faecalis eradication capacity of cysteamine, Calcium hydroxide (Ca[OH]2), TAP, $\mathrm{CHX}$, and their combinations was tested on E. Faecalis by Kirby Brauer disc diffusion method.

Results. Cysteamine in combination with TAP was able to completely eradicate E. Faecalis within 24 hours. $\mathrm{Ca}(\mathrm{OH}) 2$ was unable to show its effect on E. Faecalis in the given time.

Conclusion. Cysteamine increased the E. Faecalis eradicating capacity of TAP and also showed positive results when used in combination with $\mathrm{Ca}(\mathrm{OH}) 2$, which if used alone was unable to show any action in 24 hours.
\end{abstract}

Keywords: calcium hydroxide, chlorhexidine, cysteamine, Enterococcus Faecalis, triple antibiotic paste

\section{Introduction}

The invasion of the root canal system by bacteria leads to the onset and persistence of periapical infection. Thus, the objective of root canal treatment is to completely eliminate the bacteria from the root canals and its extensions. Although chemo-mechanical preparation effectively reduces the microbial load of the root canal, it fails to eliminate the bacteria from accessory canals, isthmi, lateral canals and apical deltas [1]. Hence, it is recommended to utilize intra-canal medicaments between the appointments to reduce bacterial counts [2].

One of the commonly isolated bacteria from persistent root canal infections is Enterococcus Faecalis (E. Faecalis). Studies have shown that E. Faecalis can penetrate deep into the dentinal tubules, hence escaping the effects of chemo-mechanical preparation during the root canal. E. Faecalis enters a non-cultivable state during root canal treatment and survives the chemo-mechanical procedures that are proven to be bactericidal. After return to a favorable environment, E. Faecalis returns into a cultureable state $[3,4]$.

Manuscript received: 10.11.2017

Accepted: 21.01.2018

Address for correspondence: drsanketpandey@gmail.com
Calcium hydroxide $\left(\mathrm{Ca}[\mathrm{OH}]_{2}\right)$ is the most widely used intra-canal medicament and shows its bactericidal activity due to high alkaline $\mathrm{pH}$. However, studies have proven that its antibacterial efficacy has been reduced in the presence of dentin $[5,6]$.

Chlorhexidine (CHX) is a broad-spectrum antibiotic and shows the property of substantivity in which it shows its antibacterial activity for a long duration when it adheres to anionic substrates [7]. Because of such properties, it is commonly used during endodontic treatments. A combination of $\mathrm{CHX}$ with $\mathrm{Ca}(\mathrm{OH})_{2}$, has been suggested previously, which has shown better results than CHX used alone [8].

Triple antibiotic paste (TAP), a mixture of metronidazole, ciprofloxacin and minocycline has been used as an intra-canal medicament to disinfect the root canal system for revascularization procedures. TAP is formed by mixing equal parts of all three antibiotics in powder form with saline or sterile water or glycerine as vehicle. This paste is sealed in the canal for 3-weeks [9].

Cysteamine is derived from cysteine and is the simplest aminothiol. The $\mathrm{pKa}$ value of cysteamine is 9.42 . It deprotonates in alkaline environment and forms thiolate ions which are responsible for breaking the disulfide bond of bacterial proteins due to which proteins are denatured 
and bacteria lose their structural integrity. One possible future implication of cysteamine in endodontics is due to its mucolytic property, making it highly effective against different types of bacteria present in biofilms in the root canal. Breaking of mucopolysaccharides by cysteamine will disrupt the structural integrity of biofilm rendering its inhabitants susceptible to various intracanal medicaments. Guo et al. recently used cysteamine and cysteamine with $\mathrm{Ca}(\mathrm{OH})_{2}$ in a study and found it to be highly effective against E. Faecalis [10]. Hence, in this study cysteamine and its combinations with various other intra-canal medicaments were used against E. Faecalis.

\section{Materials and methods}

The present study was carried out following the methods described by Kirby, Bauer, Sherris and Turck [11]. In the Kirby Bauer method, the agar plate is seeded with the bacteria. The antibiotic discs are then placed on the bacteria seeded agar plate. When discs containing known concentration of antimicrobials are placed on the surface of inoculated plate, antimicrobial agents begin to diffuse and thus establish a concentration gradient around the disc. The highest concentration is closest to the disc. After incubation at $37^{\circ} \mathrm{C}$ for 24 hours, growth of microorganisms are seen on the plate except where the concentration of disc is sufficiently high enough to inhibit the growth. Following incubation, the diameter of the zone of inhibition around each disc is measured in millimeters with the help of an inhibition zone measuring scale. An inhibition zone measuring scale is used to measure the diameter of inhibition zone in millimeters around the disc.

\section{Preparation of sample solutions}

Solution of $200 \mathrm{mg} / \mathrm{mL}$ cysteamine (LobaChemie, Mumbai, India) was prepared in distilled water (Amanta Healthcare, Gujarat, India). Saturated $\mathrm{Ca}(\mathrm{OH})_{2}$ (Prime Dental, Thane, India) solution was prepared fresh by dissolving $\mathrm{Ca}(\mathrm{OH})_{2}$ powder in distilled water. Combination of cysteamine and $\mathrm{Ca}(\mathrm{OH})_{2}$ was prepared by dissolving cysteamine in $\mathrm{Ca}(\mathrm{OH})_{2}$ solution at a concentration of $10 \mathrm{mg} / \mathrm{mL}$. TAP was formed by combining $200 \mathrm{mg}$ ciprofloxacin, metronidazole $500 \mathrm{mg}$ and minocycline $100 \mathrm{mg}$ using propylene glycol as vehicle. Combination of cysteamine and TAP was done by dissolving cysteamine in TAP at a concentration of $10 \mathrm{mg} / \mathrm{mL}$. Combination of $\mathrm{CHX}$ with $\mathrm{Ca}(\mathrm{OH})_{2}$ was prepared by dissolving $\mathrm{Ca}(\mathrm{OH})_{2}$ at a concentration of $10 \mathrm{mg} / \mathrm{ml}$ in $\mathrm{CHX}$. All the solutions were filter sterilized by using $0.2 \mathrm{~mm}$ syringe filter.

\section{E. Faecalis culture}

E. Faecalis was coated on Brain heart infusion agar by means of a sterile swab. A sterile forceps were used to dip the blank sensitivity disc in the prepared solutions followed by placing the coated sensitivity disc in the agar plates having E. Faecalis. The samples were then incubated for 24 -hours at $37^{\circ} \mathrm{C}$. Diameters of zone of inhibition were then measured after 24-hours (Figure 1).

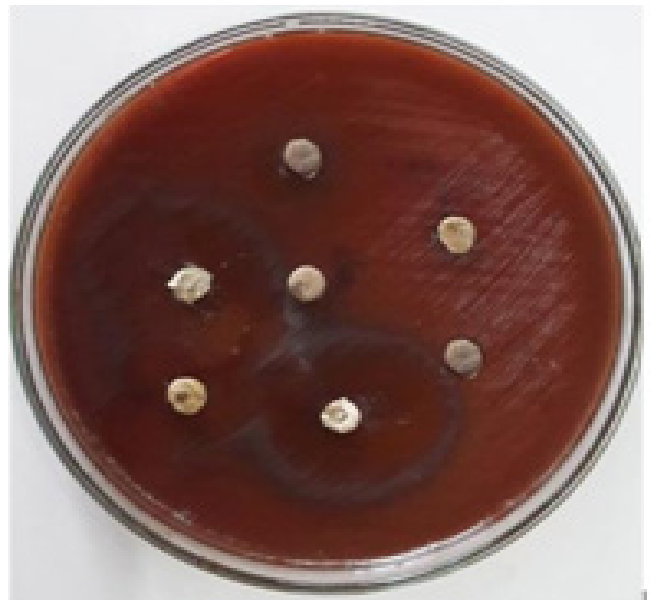

Figure 1. Photograph showing representative samples of all the groups using disc diffusion method.

\section{Statistical analysis}

All experiments were performed 3 independent times and each time in triplicate. Results were presented as the mean \pm standard deviation. Statistical significance was determined by One-way analysis of variance (ANOVA) with the Tukey post-hoc test. Differences were considered significant at $(\mathrm{p}<0.001)$.

\section{Results}

Diameters of zone of inhibition were measured for all the groups in millimeters ( $\mathrm{mm}$ ) (Table I). Maximum zone of inhibition was seen with the combination of TAP and cysteamine while $\mathrm{Ca}(\mathrm{OH})_{2}$ completely failed to prevent the growth of E. Faecalis (Figure 2). Differences between all the groups were significant except between $\mathrm{Ca}(\mathrm{OH})_{2}$ compared to control group, and cysteamine with $\mathrm{Ca}(\mathrm{OH})_{2}$ compared to $\mathrm{CHX}$ with $\mathrm{Ca}(\mathrm{OH})_{2}$.

Table I. Antibacterial efficacy of different intracanal medicaments (Values in $\mathrm{mm}$ ).

\begin{tabular}{|c|c|c|c|}
\hline & SAMPLE 1(mm) & SAMPLE 2 (mm) & SAMPLE 3(mm) \\
\hline Cysteamine & 8 & 11 & 9 \\
\hline Calcium hydroxide & 0 & 0 & 0 \\
\hline TAP & 26 & 28 & 25 \\
\hline Cysteamine $+\mathrm{Ca}(\mathrm{OH})^{2}$ & 16 & 21 & 15 \\
\hline Cysteamine + TAP & 29 & 33 & 30 \\
\hline $\mathrm{CHX}+\mathrm{Ca}(\mathrm{OH})^{2}$ & 14 & 16 & 15 \\
\hline Control & 0 & 0 & 0 \\
\hline
\end{tabular}




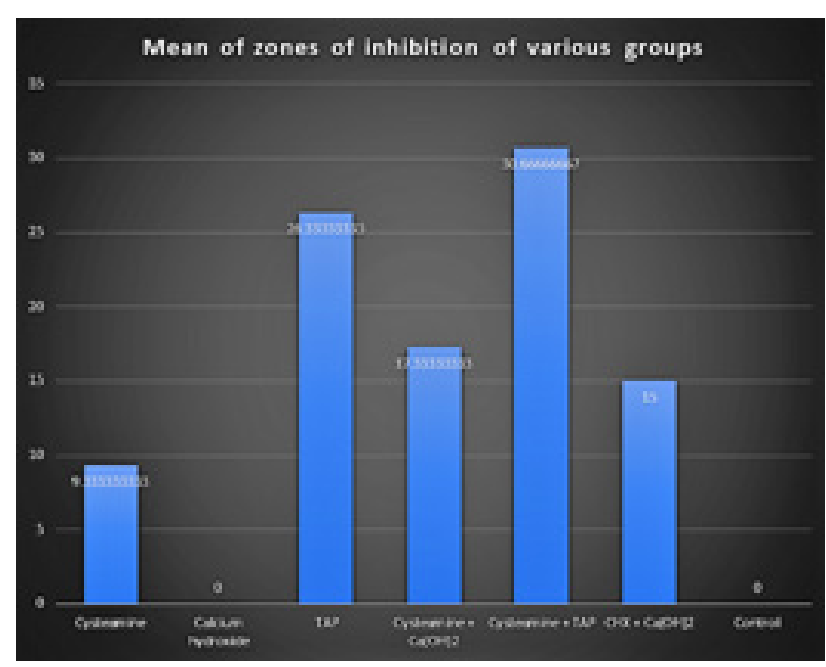

Figure 2. Graph representing comparative results (mean values) of all the groups in terms of antimicrobial efficacy.

\section{Discussion}

E. Faecalis is a predominant microorganism found in the cases where the endodontic treatment has failed [12]. Enterococci are well adapted for survival and persistence in a variety of adverse environments. This explains why it survives in root canal infections where nutrients are diminished. E. Faecalis colonized dentinal walls in case of application of endodontic medicaments. Aggregation substance, surface carbohydrates or fibronectin binding moieties favor adherence of organism to host collagen type I and extracellular matrix proteins present in the dentin. In invitro studies, E. Faecalis has been shown to invade dentinal tubules. It can colonize root canal and survive without the support of other bacteria. It is resistant to the antimicrobial effects of $\mathrm{Ca}(\mathrm{OH})_{2}[3,12]$.

The antibacterial properties of $\mathrm{Ca}(\mathrm{OH})_{2}$ are attributed to its high alkalinity and its ability to destroy the cytoplasmic membrane, denature bacterial proteins, and damage bacterial DNA. E. Faecalis is resistant to $\mathrm{Ca}(\mathrm{OH})_{2}$ because $E$. Faecalis has a proton pump which can move the protons into the cell and make the cytoplasm acidic, which is necessary to survive in high $\mathrm{pH}$ of $\mathrm{Ca}(\mathrm{OH})_{2}$ [13]. These findings contribute to our understanding of the response by E. Faecalis to the antimicrobial action of $\mathrm{Ca}(\mathrm{OH})_{2}$.

The antibiotic action of $\mathrm{Ca}(\mathrm{OH})_{2}$ is lowered by the buffering action of dentin [14]. To overcome this, addition of CHX has been introduced [15]. CHX is a cationic bisguanide that destroys the bacterial cytoplasmic membrane, leading to leakage of cellular components. It has been reported that $2 \% \mathrm{CHX}$ is more efficient than $\mathrm{Ca}(\mathrm{OH})_{2}$ in eliminating $E$. Faecalis biofilm [16]. Thus, CHX appears to be advantageous over $\mathrm{Ca}(\mathrm{OH})_{2}$ to eradicate alkaline-resistant bacteria. $\mathrm{CHX}$ causes disturbance in the bacterial membrane after penetrating into the bacteria. Bactericidal activity of $\mathrm{CHX}$ and hydroxide ions is by causing disintegration of bacterial membranes. CHX also releases reactive oxygen species which inhibits growth of E. Faecalis by destruction of cell wall and plasma membrane. An issue that has been reported is the formation of toxic parachloroaniline when CHX and sodium hypochlorite are used together. On the other hand, studies have reported that the antimicrobial activity of $\mathrm{CHX}$ is reduced when it is associated with $\mathrm{Ca}(\mathrm{OH})_{2}[8]$.

Cysteamine is formed by oxidation of cystamine, which is a radio-protective agent. It can be used intravenously or orally to treat radiation sickness. It is available in bitartarate and hydrochloride forms for the treatment of neuropathic cystinosis in young patients. Cysteamine outperforms DNAse I which is a widely used mucolytic agent in patients with cystic fibrosis. The active thiol group of cysteamine is responsible for breakage of disulfide linkages of bacterial proteins. Cysteamine exerts its biofilm eradication effects through the destruction of disulfide links [17]. In our study cysteamine showed antimicrobial activity against $E$. Faecalis within 24 hours, which $\mathrm{Ca}(\mathrm{OH})_{2}$ failed to show.

Combination of $\mathrm{Ca}(\mathrm{OH})_{2}$ and Cysteamine has shown to be bactericidal by acting synergistically. Even in the presence of $\mathrm{Ca}(\mathrm{OH}) 2$, cysteamine deprotonates and disrupts the bacterial enzymes and membranes [10]. One major implications of this result is that addition of Cysteamine decreases the amount of time required by $\mathrm{Ca}(\mathrm{OH})_{2}$ to be used as intra-canal medicament. We postulate that at a $\mathrm{pH}$ of 9 cysteamine still deprotonates and forms thiolate anions to show a synergistic anti- bacterial effect with $\mathrm{Ca}(\mathrm{OH})_{2}$.

Although the exact reason for intra canal medicaments enhancing effect of cysteamine is not yet completely understood, it may be attributed to the fact that cysteamine not just only denatures key bacterial enzymes which are important for their metabolism and survival but also causes destruction of disulfide bonds of proteins acting synergistically with the intra-canal medicament [18].

TAP has been shown to be highly effective against $E$. Faecalis. Studies $[19,20]$ have shown it to be more effective than the combination of $\mathrm{Ca}(\mathrm{OH})_{2}$ and $\mathrm{CHX}$ which was also seen in our study. The efficacy of TAP was enhanced by combining it with cysteamine. This may be attributed to the fact that cysteamine caused the breakdown of bacterial integrity which was further severed by antimicrobial effect of the mixture of other three antibiotics.

\section{Conclusion}

The presented study may have a limitation of short duration of growth of E. Faecalis as a few weeks old bacterium is found to be more resistant towards medicaments. Nevertheless, cysteamine has shown positive outcomes in in-vitro studies so far; several studies, such as its toxicity to stem cells from apical papillae and using advanced methods for antibacterial analysis, would be required to label cysteamine safe for use as intra-canal medicament for endodontic purposes. 


\section{References}

1. Antunes HS, Rôças IN, Alves FR, Siqueira JF Jr. Total and specific bacterial levels in the apical root canal system of teeth with post-treatment apical periodontitis. J Endod. 2015;41:10371042.

2. Łysakowska ME, Ciebiada-Adamiec A, Sienkiewicz M, Sokołowski J, Banaszek K. The cultivable microbiota of primary and secondary infected root canals, their susceptibility to antibiotics and association with the signs and symptoms of infection. Int Endod J. 2016;49:422-430.

3. Delboni MG, Gomes BP, Francisco PA, Teixeira FB, Drake D. Diversity of enterococcus faecalis genotypes from multiple oral sites associated with endodontic failure using repetitive sequence-based polymerase chain reaction and arbitrarily primed polymerase chain reaction. J Endod. 2017;43:377-382.

4. Henriques LC, de Brito LC, Tavares WL, Teles RP, Vieira LQ, Teles FR, Sobrinho AP. Microbial ecosystem analysis in root canal infections refractory to endodontic treatment. J Endod. 2016;42:1239-1245.

5. Zancan RF, Vivan RR, Milanda Lopes MR, Weckwerth PH, de Andrade FB, Ponce JB, et al. Antimicrobial activity and physicochemical properties of calcium hydroxide pastes used as intracanal medication. J Endod. 2016;42:1822-1828.

6. Sathorn C, Parashos P, Messer H. Antibacterial efficacy of calcium hydroxide intracanal dressing: a systematic review and meta-analysis. Int Endod J. 2007;40:2-10.

7. Torabinejad M, Walton RE. Endodontics: Principles and Practice. St Louis, MO: Elsevier Health Sciences, 2008, p 279.

8. Saatchi M, Shokraneh A, Navaei H, Maracy MR, Shojaei H. Antibacterial effect of calcium hydroxide combined with chlorhexidine on Enterococcus faecalis: a systematic review and meta-analysis. J Appl Oral Sci. 2014;22:356-365.

9. Deniz Sungur D, Aksel H, Purali N. Effect of a low surface tension vehicle on the dentinal tubule penetration of calcium hydroxide and triple antibiotic paste. J Endod. 2017; 43(3):452-455.

10. Guo W, Quah SY, Lim KC, Yu VS, Tan KS. Cysteamine enhances biofilm eradication efficacy of calcium hydroxide. J Endod. 2016;42:742-746.

11. Shenoi PR, Morey ES, Makade CS, Gunwal MK, Khode RT, Wanmali SS. In vitro evaluation of the antimicrobial efficacy of chitosan and other endodontic irrigants against Enterococcus faecalis. Gen Dent. 2016;64:60-63.

12. Cheng X, Tian Y, Zhao C, Qu T, Ma C, Liu X, et al. Bactericidal effect of strong acid electrolyzed water against flow enterococcus faecalis biofilms. J Endod. 2016;42:1120-1125.

13. Portenier I, Haapasalo H, Rye A, Waltimo T, Ørstavik $\mathrm{D}$, Haapasalo M. Inactivation of root canal medicaments by dentine, hydroxylapatite and bovine serum albumin. Int Endod J. 2001;34:184-188.

14. Sjögren U, Figdor D, Persson S, Sundqvist G. Influence of infection at the time of root filling on the outcome of endodontic treatment of teeth with apical periodontitis. Int Endod J. 1997;30:297-306.

15. Tagelsir A, Yassen GH, Gomez GF, Gregory RL. Effect of antimicrobials used in regenerative endodontic procedures on 3-week-old Enterococcus faecalis biofilm. J Endod. 2016;42:258262.

16. Ferreira NS, Martinho FC, Cardoso FG, Nascimento GG, Carvalho CA, Valera MC. Microbiological profile resistant to different intracanal medications in primary endodontic infections. J Endod. 2015;41:824-830.

17. Sevier CS, Kaiser CA. Formation and transfer of disulphide bonds in living cells. Nat Rev Mol Cell Biol. 2002;3:836-847.

18. Evans M, Davies JK, Sundqvist G, Figdor D. Mechanisms involved in the resistance of Enterococcus faecalis to calcium hydroxide. Int Endod J. 2002;35:221-228.

19. Kontakiotis EG, Filippatos CG, Tzanetakis GN, Agrafioti A. Regenerative endodontic therapy: a data analysis of clinical protocols. J Endod. 2015;41:146-154.

20. Mozayeni MA, Haeri A, Dianat O, Jafari AR. Antimicrobial effects of four intracanal medicaments on enterococcus faecalis: an in vitro study. Iran Endod J. 2014;9:195-198. 